\title{
Sağ Akciğer Agenezisi; İole ve Eşlik Eden Anomalilerle Birlikte
}

\author{
Right Lung Agenesis; Isolated and with Accompanied Anomalies
}

Yakup Canitez, Şükrü Çekiç, Arif Gürpınar*, Nihat Sapan

Uludağ Üniversitesi Tıp Fakültesi, Çocuk Sağlı̆ı ve Hastalıkları Anabilim Dall, Çocuk Alerji Bilim Dall, Bursa, Türkiye

*Uludağ Üniversitesi Tip Fakültesi, Çocuk Cerrahisi Anabilim Dalı, Bursa, Türkiye

Yazışma Adresi/Address for Correspondence Dr. Yakup Canitez, Uludağ Üniversitesi Tip Fakültesi, Çocuk Sağı̆̆ı ve Hastallkları Anabilim Dall, Çocuk Alerii Bilim Dall, Bursa, Türkiye Tel.: + 902242950404 E-posta: canitez@uludag.edu.tr

Geliş Tarihi/Received: 09.07.2013 Kabul Tarihi/Accepted: 22.07.2013

(c) Güncel Pediatri Dergisi, Galenos Yayınevi tarafindan basilmıştir.

(c) The Journal of Current Pediatrics, published by Galenos Publishing.

\section{ÖZT}

Sağ akciğer agenezisi; izole veya kalp, iskelet ve üriner sistem gibi sistemlere ait anomalilerle birlikte görülebilen nadir bir anomalidir. Olgu 1, Dört aylık bir kız çocuğu olup solunum sıkıntısı nedeniyle getirimişti. Hastada sağ el başparmakta sindaktili ve polidaktili, sağda mandibuler hipoplazisi ile dismorfik düşük kulak vardı. Akciğer grafisi ve toraks bilgisayarlı tomografisi (BT) sağ pulmoner agenezi ile uyumluydu ve 7. torakal seviyede kelebek vertebra vardl. Toraks BT anjiografide; aort, sol pulmoner arter ve sağ atriyum basilarına bağlı sol ana bronşta ve özofagusda daralma saptandı. Bronkoskopide karina düzeyinde basıya bağlı darlık görüldü ve sağ ana bronş izlenmedi. Batın ultrasonografisinde sağ böbrek yerleşim anomalisi (pelvik ektopi) ve renal sintigrafide iki böbrek arasında füzyonla uyumlu görünüm vardı. Bu bulgularla hastada, sağ pulmoner ageneziye; ipsilateral radyal ray anomalisi, renal anomali, vertebral anomali ve hemifasyal mikrozominin eşlik ettiği tespit edildi. Olgu 2, On beş yaşında erkek çocuk olup, 2 aylıkken hışıltı atağı sonrası akciğer grafisi, toraks BT ve bronkoskopi ile pulmoner agenezi tanısı almıştı. Hastanın son bir yılda belirginleşen egzersizle çabuk yorulma dışında şikayeti yoktu. Fizik muayenesinde; açıklı̆ı sağa bakan hafif skolyozu vardı, sağ hemitoraksta solunum sesleri azalmıştı, kalp sesleri sağda duyuluyordu. Akciğer grafisi ve toraks BT sağ akciğer agenezisi ile uyumluydu. Ekokardiyografide anomali yoktu, batın ultrasonografisi normaldi. Unilateral akciğer agenezilerinde; eşlik eden kardiyovasküler anomaliler, toraks içi yapılardaki distorsiyonlar ve tekrarlayan enfeksiyonlar, morbidite ve mortaliteyi etkileyen başıca faktörlerdir. Burada izole ve multipl anomalilerle birlikte iki sağ akciğer agenezili olgu sunulmuştur. (Güncel Pediatri 2013; 11: 134-7)

Anahtar kelimeler: Çocuk, konjenital anomali, akciğer agenezisi

\section{SUMMARY}

Right lung agenesis is a rare anomaly that can be isolated or accompanied by system anomalies such as cardiac, skeletal or urinary systems. Case 1, a four-month-old girl, was brought because of respiratory distress. Patient had polydactyly, syndactyly of right thumb, right mandibular hypoplasia and low-set dysmorphic ears. Lung x-ray and thorax computerized tomography (CT) were consistent with right pulmonary agenesis and butterfly vertebra was evident in the 7 th thoracic level. Thoracic CT angiography revealed narrowing of the left main bronchus and esophagus due to compression of aorta, left pulmonary artery and right atrium. In bronchoscopy, narrowing due to compression at the carina level was seen and right main bronchus was not seen. In abdominal ultrasonography, right kidney placement anomaly (pelvic ectopia) was present and renal scintigraphy revealed fusion in both kidneys. With these findings, it was found that right pulmonary agenesis was accompanied by ipsilateral radial ray anomaly, renal anomaly, vertebral anomaly and hemifacial microsomia. Case 2, a fifteen-year-old male patient, was diagnosed as pulmonary agenesis via chest $x$-ray, pulmonary CT and bronchoscopy after a wheezing episode when he was 2 months old. Patient had no complaint except for exhaustion that is aggravated by exercise during last year. In physical examination, he had a mild scoliosis toward right, respiratory sounds were diminished on right hemithorax and heart sounds were heard on right side. Chest x-ray and thoracic CT were consistent with right lung agenesis. No abnormality was found in echocardiography and abdominal ultrasonography was normal. Accompanied cardiovascular anomalies, distortions of intrathoracic structures and recurrent infections are main factors that affect mortality and morbidity. Here, two cases with right lung agenesis, isolated and accompanied by multiple anomalies, were presented. (Journal of Current Pediatrics 2013; 11: 134-7)

Key words: Child, congenital abnormalities, lung agenesis 


\section{Giriș}

Akciğer agenezileri nadir görülen konjenital anomalilerdir $(1,2)$. Unilateral ya da bilateral olarak görülebilir. Sıklığı kesin olarak bilinmemekle birlikte, 10 000-12 000 doğumda 1 olarak tahmin edilmektedir (3). Unilateral akciğer agenezilerinde cinsiyet dağılımı ile sağ ve sol akciğer agenezisi görülme oranlarının benzer olduğu bildirilmektedir (4). Sağ akciğer agenezileri izole olarak görülebileceği gibi yaklașık \%50 oranında diğer organ (kardiyovasküler, iskelet sistemi, gastrointestinal sistem, genitoüriner sistem vs.) anomalileri ile birlikte de görülebilir $(5,6)$. Ayrıca akciğer agenezileri; Holt-Oram sendromu, Goldenhar anomalisi, VACTERL birlikteliği, velokardiofasiyal sendrom ve Opitz G sendromu gibi sendromların ve aksiyal mezodermal disgenezi ve Fryns sendromu gibi ipsilateral anomalilerin bir parçası olarak görülebilir (5). Prognoz, sağ akciğer agenezili hastalarda sol akciğer agenezilere göre genel olarak daha kötüdür (7). Pulmoner agenezilerde tanı, çoğunlukla hayatın ilk yıllarında konurken, nadiren erişkin yaşa kadar gecikebilmektedir. Antenatal dönemde, kardiyak malpozisyon saptanan hastaların, pulmoner ageneziler yönünden değerlendirilmesinin erken tanı için önemli olduğunu bildiren çalışmalar bulunmaktadır (1).

Akciğer agenezisi gelişiminde embriyolojik etkilenimin 4. gestasyonel hafta civarında olduğu tahmin edilmektedir, etyolojik nedenler kesin olarak bilinmemekle beraber genetik faktörler, viral enfeksiyonlar ve vitamin A eksikliğinin rol oynadığı düşünülmektedir (8).

\section{Olgu Sunumu}

Olgu 1: Dört aylık kız hasta, 1 aydır var olan solunum sıkıntısı ve hışıltı nedeniyle başvurdu. Fizik muayenede; hasta takipneikti, sağ hemitoraksta solunum sesleri azalmıştı ve sol hemitoraksta yaygın ronküsleri vardı. Hastada, sağ mandibuler hipoplazi mevcuttu ve sağ dış kulak düşük ve dismorfik görünümdeydi. Ek olarak hasta da sağ el başparmakta sindaktili ve polidaktili vardı (Resim 1a-b). Akciğer grafisinde sağda havalanma yoktu ve kalp dekstropozeydi (Resim 2a) ve 7. torakal seviyede kelebek vertebra görünümü vardı. Toraks BT'de sağda akciğer dokusu, bronş ve damar yapıları ile uyumlu görünüm yoktu (Resim 2b), toraks BT anjiografide aort ve sol pulmoner arter basılarına bağlı sol ana bronşta ve inen aort ile sağ atriyum arasında basıya bağlı özofagusta daralma mevcuttu. Bronkoskopide karina düzeyinde dıştan basıya bağlı darlık izlendi, sağ ana bronş görülmedi. Ekokardiyografi dekstropozisyon, potent foramen ovale ve sağ pulmoner arterin rudimenter olarak değerlendirilmesi dışında normaldi. Batın ultrasonografisinde (USG) sağ böbrek orta hatta pelviste ektopik yerleşimle uyumlu görünümdeydi, renal dimerkaptosüksinik asit (DMSA) sintigrafisinde sağ böbreğin üst polünden sol böbreğe füzyone olduğu ve her iki böbrekte renal aktivite tutulumunun normal sınırlarda olduğu görüldü. Kranial USG normaldi, kromozom analizinde karyotip 46 XX olarak saptandı. Mevcut bulgularla hastada, sağ pulmoner ageneziye; ipsilateral radyal ray anomalileri, renal anomali, vertebral anomali ve hemifasyal mikrozominin eşlik ettiği tespit edildi. Izlemi sürecinde özellikle ilk yılda gerekli tedavi ve önlemlerin alınmasına rağmen 6 kez hastaneye yatmasını gerektiren solunum sıkıntısı ve hışıltı atakları olan hastanın 1 yaşından sonra hastalık sıklığında azalma olduğu görüldü.

Olgu 2: On beş yaşında erkek hasta, egzersizle çabuk yorulma ve hafif nefes darlığı yakınmaları ile başvurdu. Doğum sonrası 2 aylıkken hışıtı atağı
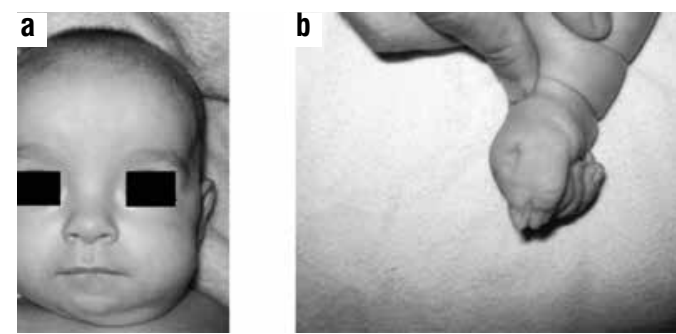

Resim 1. a) Hemifasyal mikrozomi, b) sağ el başparmakta sindaktili ve polidaktili
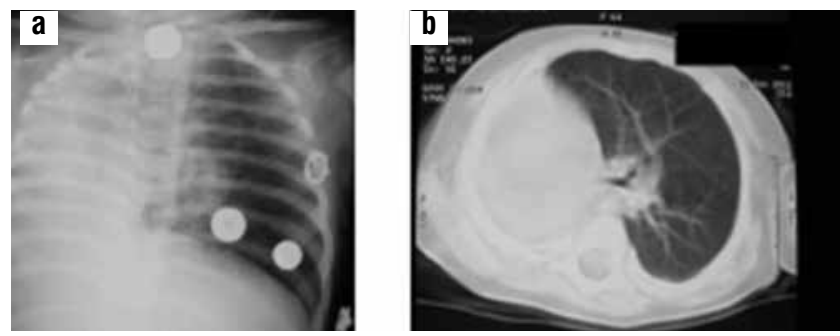

Resim 2. a) Sağ pulmoner agenezi a) akciğer grafisinde sağ hemitoraksta havalanma kaybı, b) Toraks BT'de sağ hemitoraksta akciğer dokusu ve sağ ana bronş ile dallarının görüntülenememesi, sol akciğer boyutlarında artış

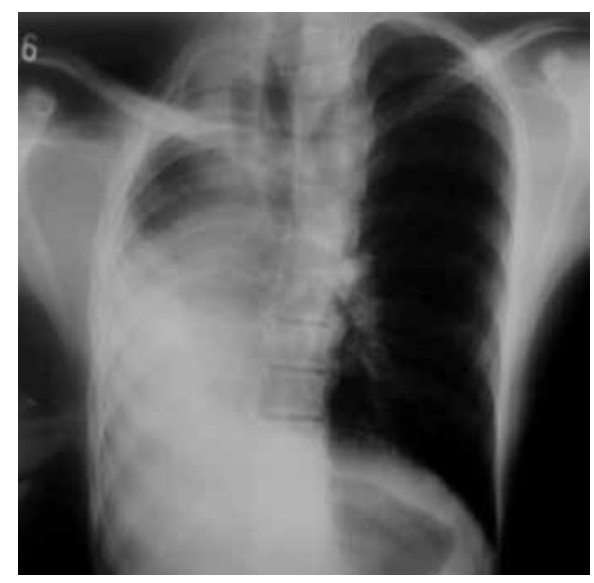

Resim 3. Sağ pulmoner agenezi; akciğer grafisinde sağ hemitoraksta havalanma azlığı, sol akciğerde ekspansiyon, skolyoz varlığı 
sırasında hastanemizde çekilen akciğer grafisinde sağ akciğer agenezisinden şüphelenilmiş, toraks bilgisayarlı tomografisi ve bronkoskopi ile tanısı kesinleştirilmişti. Iki yaşında tekrarlayan hışılı atakları nedeniyle incelendiğinde gastroözofageal reflü hastalığı tanısı konularak opere edilmiş ve hışıltı ataklarının kaybolduğu görülmüştü. Iki yaşından itibaren belirgin yakınması olmadığı ve son bir yılda egzersizle çabuk yorulma yakınmalarının belirginleştiği öğrenildi. Hastanın fizik muayenesinde; solunum sıkıntısı yoktu, açıkığı sağa bakan hafif skolyozu vardı, sağ hemitoraksta solunum sesleri azalmıştı, kalp sesleri sağ hemitoraksta duyuluyordu, diğer sistemler değerlendirildiğinde herhangi bir yapısal anomali tespit edilmedi. Akciğer grafisinde; sağ hemitoraksta havalanma tama yakın azalmıştı, sol akciğer boyutları artmıștı ve sol akciğer sağ hemitoraksa doğru ekspanse olmuştu, kalp dekstropozeydi (Resim 3). Toraks bilgisayarlı tomografide sağ ana bronş ve dalları ile sağ akciğer arter ve venleri görüntülenemedi, sol akciğer parankiminde anormal bulgu yoktu (Resim 4ab). Solunum fonksiyon testlerinde, FVC: $\% 52, \mathrm{FEV}_{1}: \% 49$, $\mathrm{FEV}_{1} / \mathrm{FVC}$ : \%94, PEF: \%38, FEF\%25/75: \%38 olarak bulundu. Solunum fonksiyon testlerinde (bronkodilatatör

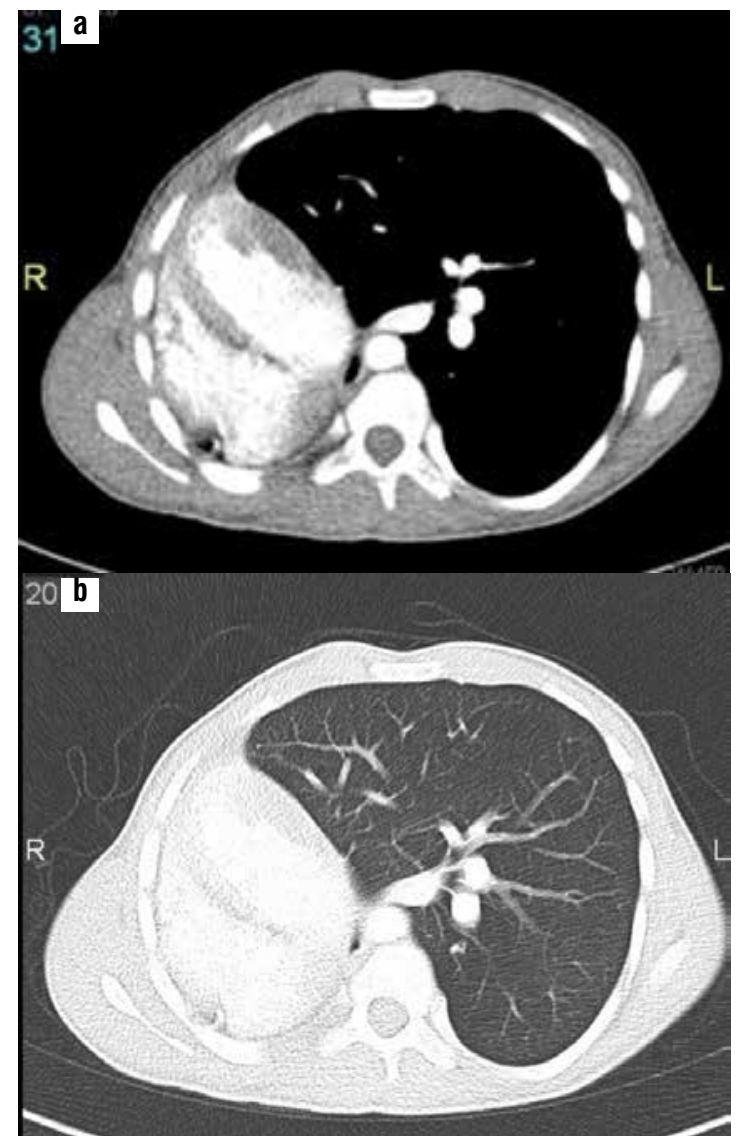

Resim 4 a,b. Sağ pulmoner agenezi; toraks BT'de sağ akciğer bronş ve damar yapılarının görüntülenememesi ile reversibilite testi ve egzersiz bronş provokasyon testi) obstrüksiyon bulgusu yoktu. Bu bulgulara ek olarak alerjenlerle deri prik testi de negatif olan hastada astım tanısı dışlandı. Ekokardiyografide yapısal anomali yoktu, batın ultrasonografisi normaldi.

\section{Tartışma}

Unilateral akciğer agenezilerinde; eşlik eden kardiyovasküler anomaliler, toraks içi yapılardaki distorsiyonlar ve tekrarlayan enfeksiyonlar mortalite ve morbiditeyi etkileyen başlıca faktörlerdir.

Akciğerin gelişimsel anomalileri patolojik olarak 3 grupta kategorize edilmektedir; agenezi (akciğer, bronş ve pulmoner arter/ven komplet yokluğu), aplazi (akciğer dokusu olmadan rudimenter bronş varlığı), hipoplazi (değişik derecelerde akciğer parankimi ve bronşlarda hipoplazi varlığı) (9).

Unilateral akciğer agenezilerinde klinik, hastadan hastaya değişkenlik göstermektedir, hastaların bir kısmı yenidoğan döneminde belirti verirken, bazı hastalar ise erişkin yaşa kadar belirti vermemekte ya da rastlantısal olarak tespit edilmektedir $(2,10)$. Sunulan iki olguda süt çocukluğu döneminde tanı almıştır.

Unilateral akciğer agenezisi olan hastalarda tabloya eşlik eden, kardiyovasküler (başlıca patent duktus arteriozus ve foramen ovale), gastrointestinal (trakeözofageal fistül ve duodenal atrezi), iskelet sistemi (hemivertebra, costa yokluğu ve radyal ray anomaliler), genitoüriner (at nalı böbrek) ve fasiyal anomaliler tarif edilmiştir $(5,11)$. Prognoz çoğunlukla eşlik eden kardiyovasküler, gastrointestinal ve genitoüriner sistem anomalilerine bağlıdır $(12,13)$. Sağ akciğer agenezilerinde prognoz, kardiyak anomalilerle birlikteliği ve kardiyak șifte bağlı gelişen büyük damar ve trakeobronşial distorsiyonlara bağlı olarak sol akciğer agenezilerine nazaran genellikle daha kötüdür (7). Sunulan 1. olguda sağ akciğer agenezisine; polidaktili, sindaktili, hemifasyal mikrozomi, patent foramen ovale, renal anomali ve kelebek vertebra gibi anomaliler eşlik ederken 2. olguda ise sağ akciğer agenezisine eşlik edebilecek diğer organ anomalileri bulunmamaktaydı. GÖR operasyonu sonrası 2. olguda hışıltı atakları kaybolmuş ve hasta hafif yakınmalarla yaşamını sürdürmüşken, 1. olguda basıya sekonder oluşan özofagus darlı̆̆ı sonucu gelişen aspirasyonlar, sık alt solunum yolu enfeksiyonları, tekrarlayan hışiltı ve solunum sıkıntısı atakları ile sık hastaneye yatma öyküsü olduğu görülmüștür.

Her iki olguda da sağ akciğer agenezileri ile birlikte görülebilen; Goldenhar anomali, VACTERL birlikteliği, velokardiofasiyal sendrom, Holt-Oram sendromu ve Opitz $G$ sendromu, Fryns ve aksiyal mezodermal disgenezi gibi sendromlar, bu sendromlara ait belirti ve bulguların olmayışı ile dışlandı. 
Akciğer agenezilerinde tanı esas olarak görüntüleme yöntemlerine dayanmaktadır. Akciğer grafisi ve toraks BT'de agenezik tarafta havalanmanın olmaması, sağlam tarafta aşırı havalanmaya bağlı genişleme, kalp ve diğer orta hat yapılarında sağlam akciğerdeki genişlemeye sekonder gelișen yer değissikliği, agenezik tarafta damar ve bronş yapılarının görüntülenememesi tanıya yardımcı olan bulgulardır. Eşlik eden kardiyovasküler anomalilerin tespit edilmesi için ekokardiyografi, vasküler anomalilerin gösterilmesi için BT anjiografi veya manyetik rezonans görüntüleme ve tanının doğrulanması için bronkoskopi kullanılabilir $(14,15)$. Sunulan her iki olgunun akciğer grafilerinde sağda havalanma olmaması, sol akciğerin sağ akciğeri kompanse etmek için genişlemesi ve sağa doğru kayması sağ akciğer agenezisini düşündüren bulgulardı. Her iki olguda da kesin tanı; toraks bilgisayarlı tomografilerinde sağ akciğere ait parankim, bronș ve damar yapılarının görüntülenememesi ve bronkoskopilerinde sağ ana bronşun olmadığının görülmesi ile konmuştur.

Akciğer agenezi ya da hipoplazili hastalarda fonksiyonel akciğer dokusunun azalmaya bağlı olarak vital kapasite düşebilir. Literatürde tek akciğer için beklenen değerlerin belirlenmemiş olmaması, bu hastalarda solunum fonksiyon testlerinin tanı ve izlemdeki etkinliğini kısıtlamaktadır. Sunulan 2. olguda total akciğer kapasitesinin azlığına bağı olarak solunum fonksiyon testi hacim ve akım hızlarında belirgin düşüklük göstermekteydi, $\mathrm{FEV}_{1} / \mathrm{FVC}^{\prime}$ nin $\% 94$ olması, bronkodilatatörlü reversibilite testi ve egzersiz provokasyon testlerinin normal olması, hastada obstrüktif patern olmadığı lehinde değerlendirildi.

Akciğer agenezilerinde tedavi, eşlik eden anomaliler ve gelişen komplikasyonlara yönelik olarak değişmektedir. Bronş veya trakeaya basının eşlik ettiği durumlarda; stent veya T tüp yerleştirilmesi, trakea ve bronşları destekleme metodlarının uygulanması, bası oluşturan nedenlerin cerrahi olarak ortadan kaldırıması (aortopeksi vb.) veya şifte bağlı distorsiyonları engellemek için toraks içi protez yerleştirilmesi gibi tedavi yöntemleri uygulanabilir (16). Asemptomatik hastalar tedavisiz takip edilebilirken, akciğer enfeksiyonları ve gelişen diğer akciğer hastalıkları erken tedavi edilmeli, pulmoner hipertansiyon gelişimi açısından dikkatli olunmalıdır.

Sonuç olarak, unilateral akciğer agenezilerinde eşlik eden anomaliler, toraks içi yapılardaki distorsiyonlar, tekrarlayan enfeksiyonlar prognoz ve morbiditeyi etkileyen başlıca faktörlerdir. Sunulan olgularda da görüldüğü gibi, sağ akciğer agenezilerinin eşlik eden diğer anomaliler ve tekrarlayan enfeksiyonlarla komplike olmadığında iyi klinik seyre sahip olabileceği, semptomatik olduğu dönemlerde tanınmadığında tanının gecikebileceği göz önünde bulundurulmalıdır.

\section{Kaynaklar}

1. Zhang Y, Fan M, Ren WD, Xie LM, Ding CW, Sun W, et al. Prenatal diagnosis of fetal unilateral lung agenesis complicated with cardiac malposition. BMC Pregnancy Childbirth 2013;13:79.

2. Yetim TD, Bayaroğullari H, Yalçin HP, Arıca V, Arıca SG. Congenital Agenesis of the Left Lung: A Rare Case. J Clin Imaging Sci 2011;1:47.

3. Fraser RG, Pare JAP. Developmental anomalies affecting the airways and lung parenchyma. In: Fraser RG, Pare JAP, Eds. Fraser and Pare's Diagnosis of Diseases of the Chest. Philadelphia: W.B. Saunders Company, 1999:597-635.

4. Maltz DL, Nadas AS. Agenesis of the lung: presentation of eight new cases and review of the literature. Pediatrics 1968;42:17588.

5. Hastings R, Harding D, Donaldson A, Liebling R, Hayes A, Kraus $A$, et al. Mardini-nyhan association (lung agenesis, congenital heart, and thumb anomalies): Three new cases and possible recurrence in a sib, is there a distinct recessive syndrome? Am J Med Genet A 2009;149:2838-42.

6. Downard CD, Kim HB, Laningham F, Fishman SJ. Esophageal atresia, duodenal atresia and unilateral lung agenesis: A Case Report. J Pediatr Surg 2004;39:1283-5.

7. Ootaki Y, Yamaguchi M, Yoshimura N, Oka S. Pulmonary agenesis with congenital heart disease. Pediatr Cardiol 2004;25:145-8.

8. Currarino G, Williams B. Causes of congenital unilateral pulmonary hypoplasia: a study of 33 cases. Pediatr Radiol 1985;15:15-24.

9. Schneider P, Schwalbe E. Die morphologic der missbildungen des menschen und der thiere. Jena: Fischer 1912;3:812-22.

10. Hacıevliyagil SS, Günen H, Yetkin Ö, Gülbaş G, Mutlu CM, Kılıç T. Asymptomatic Pulmonary Agenesis: Our Experience with Two Cases. Turkish Respiratory Journal 2006;7:31-3.

11. Mühlhausen GM, Arcil GG. Right lung agenesis in a newborn. Rev Chil Pediatr 1992;63:39-42.

12. Cunningham ML, Mann N. Pulmonary agenesis: A predictor of ipsilateral malformations. Am J Med Genet 1997;70:391-8.

13. Steadland KM, Langham MR Jr, Greene MA, Bagwell CE, Kays DW, Talbert JL. Unilateral pulmonary agenesis, esophageal atresia, and distal tracheoesophageal fistula. Ann Thorac Surg 1995;59:511-3.

14. Sharma S, Kumar S, Yaduvanshi D, Chauhan D. Isolated unilateral pulmonary agenesis. Indian Pediatr 2005;42:170-2.

15. Alvarez AJ, Vaccaro MI, Verdejo HP, et al. Pulmonary agenesis associated with multiple malformations-a case report. Rev Chil Pediatr 2000;71:41-5.

16. Laçin T, Yüksel M. Trakeobronşiyal Malazi ve Kompresyon Tedavisi. Turkiye Klinikleri J Surg Med Sci 2006;2:119-24. 